\title{
The Potential of MISTER Personal Rapid Transit to Sustain the Mobility and Development of Modern Communities
}

\author{
Richard F. Di Bona ${ }^{a^{*}}$ \\ Olgierd S. Mikosza ${ }^{b}$
}

\begin{abstract}
The Potential of MISTER Personal Rapid Transit to Sustain the Mobility and Development of Modern Communities, including: 1. Introduction: the role of transport in Schumpeterian innovation waves; 2. Key challenges faced for public transport investments: - CapEx, OpEx and the subsidy requirements of most public transit systems; - Providing a level of service sufficient to persuade motorists from their cars and making transit itself an attractive choice; - Mass personalisation in consumer markets; - The issue of pedestrian, vehicular and junction conflicts; Engineering problems with retro-fitting good solutions into existing urban environments; 3. Outlining Personal Rapid Transit (PRT), comparing some of the systems in the market place to show how Second Generation PRT could likely address the above issues and ISNGI's stated Grand Research Challenge, including: Summary results from transport modeling-based analysis; - Explanation of some features specific to MISTER PRT.
\end{abstract}

Key words: Transport; Personal Rapid Transit; Innovation; Sustainability; Mobility; Commercially Viable Public Transport; MISTER PRT

\section{Introduction}

This Paper discusses transport innovation in a Schumpeterian context, required of any true next generation infrastructure; such public transport infrastructure must be attractive to potential users, to sustain modern communities' mobility, and development. The MISTER Personal Rapid Transit system is introduced and preliminary results from EMME modelling of a potential application in the city of Opole, Poland are presented. This shows MISTER has the potential to overcome many of the challenges faced by traditional transport infrastructure solutions, not only being more attractive to potential users, but also being substantially less costly than traditional public transport; likely obviating the need for public subsidies and being much quicker to implement.

\section{Transport in Innovation Waves}

Consolidating others' preceding works, Schumpeter ${ }^{1}$ identified a series of business cycles. This included the 48-60 year Kondratieff Wave ${ }^{2}$. The Kondratieff Wave is based on the

\footnotetext{
${ }^{a}$ Independent Transport Planning Consultant, Hong Kong

${ }^{\mathrm{b}}$ President, MISTER Corporation, Auckland 1052, New Zealand

*Corresponding author: Richard Di Bona rfdibona@yahoo.com http://dx.doi.org/10.14453/isngi2013.proc.14
} 
development of new technologies, business sectors, and postulates periodic "creative destruction" as being intrinsic to industrial capitalism ${ }^{3}$. Faber ${ }^{4}$ summarised key characteristics of this cycle, including:

- Before and during the beginning of Upswings there are profound changes in industrial techniques (based on new technologies).

- Agricultural prices decrease during downswings; industrial prices hold steady or fall slightly. During upswings, commodity price increases can create broader price inflation. Interest rates also follow this cycle.

- Upswings are characterised by brevity of depressions and intensity of booms; the opposite being true during downswings.

Maddison ${ }^{5}$ estimated real global GDP per capita rose $2.90 \%$ p.a. from the 1950s-1970s (Kondratieff Wave upswing); but declined to $1.11 \%$ p.a. until the 1990's (downswing phase). Faber $^{4}$ noted the role that breakthroughs in transport technology have played in driving Kondratieff Wave upswings, namely: canals and roads (1787 onwards); railways, particularly the railroadisation of America (1842 onwards); and, aerospace (since WWII). The advent of the motor car could also be added to this list. Faber posits that the fifth Kondratieff Wave commenced around 2004, being driven by breakthroughs in telecommunications and information technology. Such breakthroughs do not occur at distinct points in time; rather, as multiple technological advancements disseminate, advancements in a number of areas eventually reach critical mass, enabling stepwise rather than merely incremental improvements. These then disseminate, ultimately reaching their own critical mass. In the case of computing, advancements have been historically described by "Moore's Law", that computing power doubles and prices halve roughly every 18 months ${ }^{6}$. This enables concepts to become cost-effective realities, in accordance with Schumpeter's observations ${ }^{1}$, driving down costs for other activities, realising wider economic gains. In part enabled by such recent breakthroughs, it could be argued that society has entered an era of mass personalisation, with aspirations and expectations now demanding increased personalisation of product and service offerings, including for urban transport.

\section{The Challenges for Next Generation Infrastructure}

The key challenge for any next generation infrastructure is to continue the process outlined above: driving down costs both to society as a whole and to the individual user, relating to both construction and operation. The benefits of such infrastructure over-and-above such cost savings should increase. For transport infrastructure, this means increasing mobility and personalisation options for the individual; underpinning sustainable development and economic growth of communities. This should be achieved within existing economic conditions, namely an era of austerity following the recent and ongoing global financial crisis. Thus cost savings are a key challenge.

\section{Key Challenges for Public Transport}

Recent history has seen tremendous growth in car ownership. Globally from 1960 to 2002 incomes rose $2.0 \%$ p.a. in real terms, whilst the motorisation rate grew $4.6 \%$ p.a. over the same 
period $^{7}$. This could be taken both as a cause and evidence of increasing aspirations for personalised transport and mobility; especially when this growth in car ownership is considered in the context of substantial investments over the same period in various, often capital-hungry public transport infrastructure projects. For example, Scholtz-Knoblach surveyed typical system capital costs per km to be US\$52-260m for heavy metro; and, US\$13-91m for light rail ${ }^{8}$.

Four-stage transport models, as described in Ortúzar and Willumsen ${ }^{9}$ take into account a wide variety of transport journey characteristics when being calibrated and used in forecasting. These can include: in-vehicle time (by mode), fares, waiting time, walk time (or distance); and, number of interchanges (given that uncertainty regarding journey times generally increases with the number of interchanges required). Yet, the performance of transport models is often poor when outturn patronage is compared against ex ante forecasts thereof, as shown in Flyvberg, et al. for mass transit projects ${ }^{10}$. Di Bona ${ }^{11}$ notes that this may be in part due to the transformational nature of introducing or significantly extending the reach of mass transit networks; but that uncertainty in rapidly evolving environments is also a contributory factor, something which current global economic uncertainty will likely cause even in traditionally stable and mature urban centres.

However, more fundamentally strategic transport models typically require substantial simplification of land use patterns (zones) and transport networks. By concentrating on the strategic overview, weak links in public transport networks, such as pedestrian severance caused by a major road, poorly maintained sidewalks, or poorly designed interchanges can result in barriers to public transport usage not considered in models ${ }^{11,12}$. Moreover, issues pertaining to institutional coordination can result in disjointed planning and nonintegrated transport networks not considered in model forecasts ${ }^{12,13}$. Added to which, due in part to issues of computing power and data availability, pedestrian level-of-service has often been under-emphasised ${ }^{13}$.

Given that such shortcomings affect the viability of transport infrastructure investments, they reduce the probability of further projects being approved ${ }^{11}$. Next generation transport infrastructure projects, in line with Schumpeter's requirements ${ }^{1}$ need to be viable despite these widespread challenges; ideally finding a way to overcome the problem of pedestrian accessibility in $\operatorname{particular}^{14}$.

\section{Personal Rapid Transit}

The Advanced Transit Association defines Personal Rapid Transit (PRT) as an automated guideway transit system in which all stations are on bypasses, the vehicles are designed for a single individual or small group (family or friends) travelling together on a segregated network, and trips are nonstop without transfers. In other words:

- PRT offers point-to-point journeys, neither requiring interchange between "lines" nor stopping at intermediate stops, so journey times are quicker even than metro.

- Stations can be much closer than metro or LRT and much smaller, so passengers do not have to walk as far to/from the system.

- Passengers travel on their own or with a small group of friends, colleagues, and/ or family, i.e. not with strangers. 
- Unlike surface level light rail or bus rapid transit, it will not interfere with the operation of traffic junctions or other road users or pedestrians.

As such, PRT could be said to offer significantly faster, safer, more comfortable journeys than traditional public transport modes. Yet due to efficiency and cost advantages, PRT can be offered to customers at fare levels similar to those charged by traditional public transport modes, without the need for subsidies. Given that stations can be 100m-300m apart (depending upon the specific PRT system) and that all PRT systems are smaller and more lightweight than monorail (not to mention metro), PRT offers improved accessibility and deeper direct market penetration than traditional rail-based transport modes: either in its own right or as a feeder to metro. Moreover, PRT could be described as having the environmental benefits of public transport (including the ability to substantially reduce road congestion), whilst offering the user a service quality akin to a private car but without traffic congestion.

\section{Description of MISTER}

Conceived in 2005 (when the first patents were filed), the Metropolitan Individual System of Transportation on Elevated Rail (MISTER) is a Personal Rapid Transit (PRT) system. Demonstrated by means of a 1:1 working prototype in Opole in 2007, MISTER subsequently underwent comprehensive technical and economic due diligence, being awarded a European High Technology Grant. As described by Mikosza ${ }^{15,16}$ and Lambo ${ }^{17}$, MISTER has inter alia the following characteristics:

- Lightweight vehicles (300kg "pods") suspended from an unobtrusive guideway suspended 8-15m above ground level.

- Can ascend or descend 45 degrees, with a 3 metre radius turning circle, so can be accommodated into almost all existing urban environments.

- $\quad$ Each pod can accommodate up to 5 persons or two both with bicycles.

- Street-level boarding with level floor, so accessible for the mobility impaired.

- No ride-sharing with strangers.

- Vehicles individually electric-powered via 'third' rail located within the guideway.

- Travel direct-to-destination (no intermediate stops) at 50-70kph; vehicles stop offline.

- Patented guideway switching ensures fail-safe operation.

- Easy, modular system expansion capabilities.

- Minimal footprint for guideway (equivalent to a lightpole's footprint).

- Significantly reduced construction costs: US\$7-10m per km (two-way track, including stops and pods).

- $\quad$ Specialised pods for freight delivery, with a capacity of up to $400 \mathrm{~kg}$ per pod.

- Can be installed at the rate of one km per month in each direction. 
International Symposium for Next Generation Infrastructure

October 1-4, 2013, Wollongong, Australia

\section{Summary Results from Modelling: Opole, Poland}

\section{A. Opole and Data Sources}

Opole is a city and provincial capital in Poland with a resident population of around 146,000 people, including a significant number of tertiary students. In 2007, MISTER exhibited a 1:1 working prototype of their PRT system in the city; and also received approval to implement MISTER in the city, subject to raising finance to proceed. Demographic, land use, and economic data (historic, existing, and forecast) were obtained from a number of sources ${ }^{18,19,20,21}$. Data on existing public transport services were obtained from operators ${ }^{22,23}$. Traffic counts and travel diaries were not available, but calibrated traffic levels and speeds, were reviewed and checked by the co-author (then resident in Opole).

\section{B. Outline of Modelling}

In order to enable detailed consideration of the MISTER network (with stops spaced more closely than train or bus stops), a detailed zoning system was developed, comprising 917 zones. Transport networks were coded to a corresponding level of detail. The model was developed using EMME. Binary mode choice was used between car using and noncar using (i.e. public transport: bus, train, walk, and in future scenarios, PRT). EMME's transit assignment algorithm was used to analyse routeings for public transport, rather than using submode split, as it is quite conceivable that PRT passengers could use bus or train for access/ egress. The forecast horizon adopted was 2050, with AM Peak, Inter-Peak, and PM Peak periods modelled separately. A $32.6 \mathrm{~km}$ network of MISTER PRT was coded into EMME and tested.

\section{Key Assumptions}

Population forecasts were based on data from Opole City ${ }^{21}$. Trip rates were based on Jastrzębski $^{24}$ and Fouquet ${ }^{25}$, taking account of income levels from Eurostat ${ }^{20}$. MISTER fare levels were assumed to be 3.40 Zloty (US\$1) for boarding plus 0.34 Zloty per km (pro rataed).

System certification was assumed to cost US\$30m and to take 18 months. Depot and control centre construction would cost US\$15m and take 6 months, concurrent with the 7 month construction of the first $(8.4 \mathrm{~km})$ phase of MISTER. Track was costed at US\$8m per km for twoway track, including stops and pods (100 pods per km of two-way track). The second phase is $9.1 \mathrm{~km}$ ( 5 months to construct); the third phase is $9.0 \mathrm{~km}$ (4 months to construct); and phase four is $6.2 \mathrm{~km}$ ( 3 months to construct). Demand ramp-up of $50 \%$ over 6 months was assumed. Based on MISTER's detailed project plans (consistent with those used for EU due diligence): a pod occupancy of 1.5 was assumed (similar to car occupancies), with annual servicing per pod costing US\$1,030. Pods travel at $55 \mathrm{kph}$, using $5 \mathrm{~kW}$ of power (US\$0.10 per $\mathrm{kW}$ ). $20 \%$ of deadheading pod kilometrage was assumed to allow for pods to match demand. MISTER staffing was assumed to be 20 plus 5 per km of two-way track (ZL70,000/ US\$20,588 per person per year).

\section{Preliminary Modelling Outputs}

For space reasons, modelling results herein are confined to summary results from preliminary year 2020 forecasts. The $32.6 \mathrm{~km}$ MISTER network would, on a daily basis:

- Increase noncar (i.e. bus, train, walk, PRT) mode share from $12 \%$ to $32 \%$.

- Give overall journey time savings for car users of $11 \%$ per trip. 
- Decrease overall fuel consumption by $21.6 \%$ citywide.

- Generate almost 153,000 boardings per day on MISTER, with over 450,000 passenger$\mathrm{km}$ travelled.

These forecasts show not only the potential attractiveness of MISTER to users, but also that a MISTER PRT network would yield sizeable journey time savings for nonusers, through decongesting the city and so boosting mobility for all.

\section{E. Internal Rate of Return (IRR)}

The Internal Rate of Return (IRR) for the project was calculated both including system certification (if this were the first MISTER roll-out in Europe), coming to 18.4\%; and with certification excluded, yielding an IRR of 20.6\%. These IRR's demonstrate that MISTER would be commercially viable without need for government subsidies, aside from access to the right of way (which as described previously does not require a large footprint). These rates of return also show that there would be sufficient margin to entertain revenue sharing with potentially cashstrapped local authorities (or to cover sales taxes on tickets, were such levied).

\section{Conclusion}

Any true next generation transport infrastructure must be cheaper and offer a vastly improved level of service relative to existing technologies. Such infrastructures should axiomatically sustain the mobility and development of modern communities (ideally being more environmentally friendly to both construct and operate). MISTER Personal Rapid Transit has been shown to require substantially less capital and operating expenditure than last generation systems. Indeed, besides access to right of way, public subsidies should be unnecessary. It is potentially highly attractive to users, overcoming many of the problems faced by orthodox public transport; this also results in wider decongestion and environmental benefits, increasing mobility for all and therefore assisting the sustainable development of modern communities. Moreover, MISTER PRT projects should offer attractive returns to investors.

\section{References}

${ }^{1}$ Schumpeter, J.A., Business Cycles: A Theoretical, Historical and Statistical Analysis of the Capitalist Process, Philadelphia, 1939.

${ }^{2}$ Kondratieff, N.D., "Die Langen Wellen der Konjunktur", Archiv für Sozialwissenschaft und Sozialpolitik, Vol. 56, No. 3, 1926, pp. 573-609.

${ }^{3}$ Schumpeter, J.A., Capitalism, Socialism and Democracy, $3^{\text {rd }}$ Edition, New York: Harper \& Brothers, 1950.

${ }^{4}$ Faber, M., Tomorrow's Gold: Asia's Age of Discovery, CLSA Books, Hong Kong, 2002.

${ }^{5}$ Maddison, A., Monitoring the World Economy, 1820-1992, Washington, D.C.: Organization for Economic Cooperation and Development, 1995.

${ }^{6}$ Moore, G.E., "Cramming More Components onto Integrated Circuits”, Electronics, 19 April 1965.

${ }^{7}$ Dargay, J., Gately, D., and Sommer, M., "Vehicle Ownership and Income Growth, Worldwide: 1960-2030”, Energy Journal, Vol. 28, No. 4, 2007. pp 163-190.

http://dx.doi.org/10.5547/ISSN0195-6574-EJ-Vol28-No4-7 
International Symposium for Next Generation Infrastructure October 1-4, 2013, Wollongong, Australia

${ }^{8}$ Scholtz-Knobloch, O., “Organizing New Light Rail Projects”, Banekonference, Copenhagen, 2012.

${ }^{9}$ Ortúzar, J.d.D. and Willumsen, L.G., Modelling Transport, $2^{\text {nd }}$ Edition, John Wiley \& Sons, 1994.

${ }^{10}$ Flyvberg, B., Hulm, M.K.S., and Buhl, S.L., "How (In)Accurate are Demand Forecasts in Public Works Projects", Journal of the American Planning Association, Vol. 71, No. 2, Spring 2005, pp. 131-146. http://dx.doi.org/10.1080/01944360508976688

${ }^{11}$ Di Bona, R.F., "Transport Modelling for Transport and Land Use Sustainability: lessons and challenges from East Asia and the Middle East", 4th Annual San Francisco Bay Area ITE Modeling Workshop, San Francisco, USA, 1 April 2011.

${ }^{12}$ Di Bona, R.F., "Weak Links in Transit Networks: Implications for Feasibility and Performance; and Possible Solutions", 6th Annual China RailWorld Summit 2011, Beijing, 23 September 2011.

${ }^{13}$ Di Bona, R.F., "Developing Attractive, Integrated Public Transport Networks in Rapidly Developing Cities", 2nd Annual Metro Expansion India Summit, New Delhi, 23-24 February 2012.

${ }^{14}$ Di Bona, R.F., "It is time we included Pedestrians in Transport Planning", TrafficInfraTech, Vol. 2, No. 3, December 2011 - January 2012, pp. 66-70.

${ }^{15}$ Mikosza, O.S., "MISTER PRT: Solution to City Traffic Problems, The Pod Car City", International PRT Conference, Uppsala, 1-2 October, 2007.

${ }^{16}$ Mikosza, O.S., "New Personal Rapid Transit (PRT) from MISTER Ltd., Poland”, United Nations Climate Change Conference (COP 14), Poznan, December 2008.

${ }^{17}$ Lambo, Z., "MISTER System”, Podcar City: Sustainable Transportation Conference, 14-16 Ithaca, New York, September, 2008.

${ }^{18}$ Central Intelligence Agency, "The World Factbook", Central Intelligence Agency Library [online database], 2013, URL: https://www.cia.gov/library/publications/the-worldfactbook/index.html

${ }^{19}$ Central Statistical Office of Poland, Statistical Yearbook of the Republic of Poland 2012, 2012, Warsaw.

${ }^{20}$ Eurostat, European Commission Eurostat Database [online database], 2013, URL: http://epp.eurostat.ec.europa.eu/portal/page/portal/eurostat/home/

${ }^{21}$ Opole City, "Via Regus Plus Project and European Union European Regional Development Fund", Analysis of Demographic Change Effects with Special Focus on the Labour Market in Opole until 2020 (Summary), 2011.

${ }^{22}$ MZK, Online Bus Timetable, Opole Bus Operator [online database], 2013, URL: www.mzkopole.pl

${ }^{23}$ PKP, Online Route Planner, Polish National Railways [online database], 2013, URL: http://www.rozklad-pkp.pl/

${ }^{24}$ Jastrzębski, W., "A Traffic Model of Warsaw”, 3rd European EMME/2 Users' Conference, Stockholm, 25 May 1994.

${ }^{25}$ Fouquet, R., "Trends in Income and Price Elasticities of Transport Demand (1850-2010)", BC3 Basque Centre for Climate Change [online database], 2013, URL: http://www.bc3research.org/lits_publications.html 